\title{
Algunas cuestiones fundamentales sobre el deber jurídico
}

Freddy Escobar Rozas

\section{Introducción}

En tiempos en los que la atención de los juristas se suele centrar -con justa razón- en la solución de los no pocos problemas que ha traído tanto el desarrollo tecnológico como el nuevo orden económico, resulta sumamente preocupante constatar el abandono en el que paulatinamente ha caído, el estudio de la teoría general del Derecho. Y es que si se tiene presente que esta disciplina es la que proporciona las herramientas indispensables que permiten interpretar y aplicar, correctamente las normas jurídicas, ' fácilmente se comprenderá lo peligroso que resulta, para el que estudia o ejerce la profesión de abogado, descuidar el cultivo de las categorías fundamentales del Derecho, pues sin el dominio de las mismas de poco servirá el manejo que se pueda tener sobre unas cuantas leyes novedosas.

1 Un ejemplo de cómo influye, en la interpretación y aplicación de la ley, la postura que se adopte sobre determinadas cuestiones vinculadas a la teoría general del Derecho, puede ser encontrado en la explicación que Manuel de la Puente y Lavalle realiza sobre los alcances del artículo $1383^{\circ}$ del Código Civil. Para quien atentamente siga el camino recorrido por este autor en su afán de sostener que sólo la incapacidad absoluta está comprendida en el supuesto de hecho del artículo en cuestión (que regula autonomía de la oferta), será fácil descubrir que su tesis rinde tributo al método de la «jurisprudencia de conceptos». Notoria es la diferencia de resultados si al amparo de otro método, el de la "jurisprudencia de intereses», se descubre que, para efectos de determinar si la oferta es o no autónoma, poco interesa si la incapacidad sobrevenida del oferente es absoluta o relativa (ver: Manuel De La Puente y Lavalle, El Contrato en General, Para Leer el Código Civil vol. XI, Lima, Fondo Editorial Pontificia Universidad Católica del Perú, 1991, parte primera, tomo II, p. 375). 
Uno de los institutos más importantes de la teoría general del Derecho es, sin duda, el deber jurídico. En efecto, el deber jurídico no sólo penetra todas las ramas del Derecho, dirigiendo o encausando los comportamientos de los sujetos a los cuales ellas se dirigen, sino que también fija el alcance de la libertad personal, tal como lo reconoce el literal a) del numeral 24) del artículo $2^{\circ}$ de nuestra Constitución.

Paradójicamente, la doctrina nacional no le ha prestado al deber jurídico la más mínima atención, ${ }^{2}$ de modo que puede afirmarse, sin temor a equívoco, que esta institución es una de las más desconocidas en el medio, hecho que lamentablemente ha traído funestas consecuencias. $^{3}$

En este poco halagador contexto, las líneas que siguen desarrollarán algunas cuestiones fundamentales del deber jurídico, tratando así de contribuir al esclarecimiento de sus contornos. Antes de empezar, es preciso advertir que no se abordará aquí, por razones de espacio, la cuestión relativa al origen del deber jurídico; origen que debe ser encontrado en la vieja obligatio romana.

2 Es justo indicar, sin embargo, que incluso la doctrina comparada ha descuidado el estudio del deber jurídico como categoría general. No en vano un jurista de la talla de Santi Romano en su momento afirmó que "Delle varie figure giuridiche soggetive, che recenti indagini si sforzano di distinguere e definire con sempre maggiore precisione, quella che è rimasta più nell'ombra ì senza dubbio la figura del dovere o dell'obbligo, ritenuta generalmente unica e promiscuamente designata con l'una o l'altra di queste due parole" (ver: Santi Romano, Doveri. Obblighi, Frammenti di un Dizionario Giuridico, Dott. A. Milano, Giuffrè Editore, 1947, p. 91).

3 Sólo el desconocimiento de la esencia del deber jurídico ( $y$, por ende, de la esencia de la obligación, que es un tipo deber jurídico) puede explicar el hecho que el legislador del Código Civil haya contemplado, por un lado, una serie de figuras contractuales cuyos efectos en ningún caso pueden ser reconducidos a la figura del deber jurídico (p.e. contrato de opción, promesa de hecho ajeno, etc.) y declarado paladinamente, por el otro, que el contrato sólo tiene efectos obligacionales, con lo que acepta y promueve -indebidamente- la aplicación de las normas relativas a las obligaciones, a relaciones contractuales cuya naturaleza impide tal cosa (paradigmática resulta a este efecto la postura de Max Arias Schreiber en torno a la promesa de hecho ajeno, desde que la misma consiste en considerar que el promitente asume una obligación de hacer -y no un estado de sujeción-. Por tal motivo, en problemas se ve el autor -aunque no lo advierta- cuando a pesar de su concepción sobre los efectos de este contrato, sostiene, por ejemplo, que ante la muerte del tercero -caso fortuito- el promitente -deudordebe pagar la indemnización. Ver: Max Arias Schreiber, Exégesis, Lima, Librería Studium Ediciones, 1986, tomo I, p. 286). 


\section{El deber jurídico como situación jurídica subjetiva}

Según la apreciación unánime de la doctrina, ${ }^{4}$ el ordenamiento jurídico no es sino un conjunto de normas que operan sobre el dato de la realidad humana, el cual está representado por intereses y actividades que se desarrollan sobre el plano social. La función que aquel ordenamiento cumple con esta intervención consiste en valorar, tutelar y dirigir la efectiva realización de una serie de actividades y, por ende, la satisfacción de un conjunto de intereses.

Ahora bien, esta función es efectuada con un fin específico que fundamenta la existencia del ordenamiento jurídico y justifica incluso su imposición coactiva: el logro de la pacífica convivencia entre los seres humanos. ${ }^{5}$ Para alcanzar este supremo fin resulta indispensable, empero, que los sujetos que conforman la comunidad vean realizados, en alguna forma, los intereses que su propia naturaleza humana les plantea; pues, de lo contrario, la posibilidad de que los mismos convivan de manera pacífica se tornaría sumamente remota. Y aquí hay fundamentalmente dos opciones a tomar: o el Estado -o la organización que haga sus veces- satisface directamente los intereses de sus súbditos o se les deja a éstos la tarea de hacerlo. Si se escoge esta segunda opción, como ocurre siempre, en menor o mayor medida, el ordenamiento jurídico debe otorgar las herramientas necesarias para el efecto. Dichas herramientas son las denominadas, «situaciones jurídicas subjetivas».

Según una autorizada opinión, ${ }^{6}$ la "situación», en general, es un elemento de la existencia; y ésta, a su vez, es estar en el mundo y poder darse forma.

Cuando se habla de "situación jurídica subjetiva", sin embargo, no se alude a otra cosa que a la posición que asume el sujeto frente a las reglas de Derecho. ${ }^{7}$ En consecuencia, dicha situación puede ser defini-

4 Así: Vittorio Frosini, La Estructura del Derecho, traducido por Antonio Enrique Pérez Luño y M. J. Magaldi Paternosto, Bologna, Publicaciones del Real Colegio de España, 1974, p. 35; Rosario Nicolò, Le Situazioni Giuridiche Soggetive, Letture di Diritto Civile, raccolte da Guido Alpa e Paolo Zatti, Cedam, Padova, 1990, p. 129.

5 Así: Pietro Trimarchi, Istituzioni di Diritto Privato, Milano, Giuffrè Editore, 1989, p. 44.

6 Luis Legaz y Lacambra, Introducción a la Ciencia del Derecho, Barcelona, Bosch Casa Editorial, 1943, pp. 540 y 541.

7 En tal sentido: Paolo Zatti y Vittorio Colussi, Lineamenti di Diritto Privato, Casa Editrice Dott. Antonio Milani, Padova, 1989, p. 63; Umberto Breccia; Lina Bigliazzi Geri; 
da como una "circunstancia» de la existencia jurídica personal, en la cual están contenidas en potencia una o más posibilidades de la vida del sujeto (de derecho), con arreglo a las cuales (i) se satisface un interés -considerado "digno»- o (ii) se sacrifica otro. ${ }^{8}$

Ahora bien, así entendida la situación jurídica subjetiva, es a todas luces claro que ella no puede ser considerada como "fenómeno" que subsume a la relación jurídica intersubjetiva, ya que, por definición, ésta es un simple vínculo que une algo que "afecta" a cada uno de los individuos que son parte activa y pasiva en la misma. Y ese "algo", por cierto, no es otra cosa que la situación jurídica subjetiva, en tanto que ésta constituye una determinada manera de estar respecto de los preceptos que conforman el derecho objetivo.

Sobre la situación jurídica subjetiva, repetidamente se ha afirmado, y con razón, que ha conseguido desplazar al derecho subjetivo en su función de concepto central del Derecho. Pero hay que ser cuidadosos. La situación jurídica subjetiva no ha superado, como afirman algunos, ${ }^{9}$ al derecho subjetivo sobre la base de «enriquecer» su «unidimensionalidad ${ }^{10}$ En realidad, la referida situación ha reemplazado al men-

Ugo Natoli; Francesco Busnelli D.: Derecho Civil, traducido por Fernando Hinestroza, Bogotá, Universidad Externado, 1992, tomo I, vol. I, p. 352.

8 Sustancialmente conformes: Giorgio De Semo, Istituzioni di Diritto Privato, Firenze, G. Barbera Editore, 1952, p. 897; Luis Legaz y Lacambra, op. cit., p. 541.

9 Carlos Fernández Sessarego, Abuso del Derecho, Buenos Aires, Editorial Astrea de Alfredo y Ricardo Depalma S.R.L., 1992, p. 65 y ss.

10 La afirmación de que el concepto de derecho subjetivo es "unidimensional" (situación pura de libertad) y por ello "limitado" (en su significado de «insuficiente") no puede ser compartida. Así, no existe defecto alguno que se le pueda reprochar a este concepto, en tanto que la presencia de una situación de necesidad, que es la "opuesta» a la contemplada en el mismo, resulta imposible. Esto no significa, ciertamente, que el derecho subjetivo no conozca una serie de límites. Pero de ahí a sostener la necesaria ubidimensionalidad" de su concepto (lo que significa incorporar en éste al deber), hay un paso que por mandato de la razón no puede ser dado. Por ello, afirmar, como lo hace Fernández Sessarego, que el «[...] derecho subjetivo incluye, simultáneamente y en su propia entraña, un deber [...]" (El histórico problema de la capacidad jurídica, Código Civil Peruano. Diez Años. Balances y Perspectivas, Lima, Universidad de Lima, 1995, tomo I, p.102); y, peor aún, que ambos (derecho y deber) conforman un concepto mayor como el de "situación jurídica subjetiva" (op. cit., p. 103), es extraviarse; pues no se entiende cómo un derecho subjetivo puede incluir un deber jurídico, desde que resulta imposible afirmar -salvo que en el discurso empleado la coherencia constituya algo de lo que se pueda prescindir- que un individuo tiene, a la vez, la libertad y la necesidad de hacer algo. Y en defensa de la tesis criticada no cabe acudir, como lo hace Fernández Sessarego, a casos como el previsto en el artículo $19^{\circ}$ de nuestro Código Civil, según el cual toda persona 
cionado derecho -en su papel de "partícula" fundamental del ordenamiento- por comprender dentro de sí a una pluralidad de "posiciones" que, «afectando" a los sujetos, no pueden ser reconducidas a los esquemas de la facultas agendi.

La situación jurídica subjetiva, en tanto "posición» del sujeto frente a las reglas de Derecho -las cuales tienen como función resolver los conflictos de intereses-, no puede sino responder a una determinada valoración del ordenamiento jurídico respecto de la primacía o la subordinación del interés que le sirve de presupuesto. En efecto, si, como anteriormente se indicó, los individuos que conforman una sociedad requieren satisfacer sus distintos intereses, a fin de que se creen las condiciones necesarias para el logro de una "pacífica convivencia", el conjunto de reglas que los regula necesariamente tiene que establecer las formas para alcanzar aquel propósito -esto es, la realización de los referidos intereses-. Y como quiera que frente a los bienes «insuficientes" la solución que se adopte va a significar, en cualquier caso, el sacrificio de un interés, la situación jurídica subjetiva tiene que reflejar o la «supremacía» o la "subordinación" del mismo.

Cuando ocurre lo primero, esto es, cuando la situación jurídica subjetiva refleja la «supremacía» de un interés frente a otro, se dice que la misma es de ventaja. En este sentido, se ha definido a esta clase de situación como aquella que, considerando un particular interés, garantiza a quien lo experimenta la obtención de su realización. ${ }^{11}$ Cuando ocurre lo segundo, esto es, cuando la situación jurídica subjetiva refleja la «subordinación" de un interés frente a otro, se dice que la misma es de desventaja. En este sentido, se ha definido ${ }^{12}$ a esta clase de situación

tiene el derecho y el deber de llevar un nombre, ya que es claro que el referente objetivo del derecho de llevar un nombre es distinto del referente objetivo del deber de hacerlo, de donde se sigue sin dificultad que este último no puede estar alojado en la entraña del primero. Lo dicho, obviamente, no supone que no existan situaciones complejas -resaltamos el adjetivo calificativo- en las cuales el individuo sea portador de derechos, deberes, cargas, intereses legitimos, etc. Pero nótese que una cosa es decir que, por ejemplo, por el hecho de ser parte compradora tengo una serie de derechos y deberes, y otra muy distinta que por ser titular del derecho de exigir la entrega del bien ostento deberes que forman parte de aquél.

11 Así: Umberto Breccia; Lina Bigliazzi Geri; Ugo Natoli; Francesco D. Busnelli, op. cit., tomo I, vol. I, p. 353.

12 Así: Umberto Breccia; Lina Bigliazzi Geri; Ugo Natoli; Francesco D. Busnelli, op. cit., tomo I, vol. I, p. 355. 
como aquella que impone un «sacrificio» a su titular, a fin de asegurarle una situación jurídica subjetiva -de ventaja- vinculada, su existencia o su realización.

Ahora bien, la situación jurídica subjetiva de ventaja puede ser, a su vez, activa o inactiva, cosa que depende de la posibilidad de obrar que acuerde para su titular en relación con la satisfacción de su interés. Así, es «activa" la situación si es que permite obrar para realizar el interés que le sirve de presupuesto; e «inactiva» si es que, por el contrario, no permite obrar para obtener dicho resultado. ${ }^{13}$ Vistas de esta manera las cosas, se puede afirmar que constituyen situaciones jurídicas subjetivas de ventaja activas, el derecho subjetivo y el poder jurídico; y que constituye una situación jurídica subjetiva de ventaja inactiva, el interés legítimo. ${ }^{14}$

13 Así: Umberto Breccia; Lina Bigliazzi Geri; Ugo Natoli; Francesco D. Busnelli, op. cit., tomo I, vol. I, p. 356.

14 Conviene aclarar, sin embargo, que éstas no son las únicas situaciones jurídicas subjetivas de ventaja que existen, pues es perfectamente factible encontrar una serie de situaciones «innominadas" que, sea por "proteger" o por "subordinar" cierto interés, deben ser incluidas dentro de las categorías estudiadas. A título de ejemplo, puede citarse como situación jurídica subjetiva de ventaja innominada a la que ostenta el propietario (o más genéricamente, al titular de un derecho real) frente a los terceros que están impedidos de actuar sobre la cosa objeto de su derecho. En efecto, dicha situación no puede ser reconducida-como equivocadamente se ha pretendido hasta no hace mucho- a la figura del derecho subjetivo, en tanto que el propietario carece de facultad de obrar para satisfacer su interés. Así, reconociendo que, respecto de dichos terceros, el interés del propietario consiste en que éstos no interfieran en el libre goce de la cosa, resulta claro que el propietario no tiene pretensión alguna frente a los mismos, ya que no puede exigirles la realización de conducta alguna (si lo hace, esto es, si efectivamente el propietario exige a tales terceros, mediante una manifestación de voluntad expresa o tácita, el "respeto de su derecho" -o, lo que es lo mismo, el cumplimiento del deber genérico de no interferir en la esfera ajena-, ninguna consecuencia jurídica se derivará, de donde se sigue que para el ordenamiento jurídico es absolutamente indiferente la actitud asumida por aquel). Es cierto que el propietario puede obrar cuando los terceros violan el deber genérico a su cargo -o cuando existe el peligro de que ello ocurra-; pero es cierto también que la posibilidad de hacerlo (a través del ejercicio de las acciones posesorias e interdictales) se reconduce, no a su derecho de propiedad, sino a los mecanismos de tutela de la posesión. Por lo tanto, es claro que, en una situación de normalidad, el propietario carece de pretensiones (y en general de derechos) contra los terceros que de hecho pueden actuar sobre el objeto de su derecho. Esto no significa, sin embargo, que dicho propietario carezca de una situación jurídica subjetiva de ventaja frente a tales terceros, ya que el interés que tiene en no ser interferido en el libre goce de la cosa sobre la cual recae su derecho resulta valorado positivamente por el ordenamiento, en tanto que éste conecta, por un lado, un deber genérico tendiente a la satisfacción de dicho interés; y otorga, por el otro, medios de protección frente a la lesión -o el peligro de lesióndel mismo. Lo que ocurre es que la posición de ventaja que tiene el propietario no puede ser reconducida a las viejas figuras del derecho subjetivo y el interés legítimo. 
Por su parte, la situación jurídica subjetiva de desventaja puede ser, también, activa o inactiva, dependiendo de si su titular debe o no obrar para actuar su contenido (o para "cumplirlas"). En este sentido, se puede afirmar que el deber jurídico y la carga constituyen los dos supuestos de situación jurídica subjetiva de desventaja activa, mientras que la sujeción constituye el único supuesto de situación jurídica subjetiva de desventaja inactiva.

\section{Teorías sobre la esencia del deber jurídico}

Como se acaba de ver, el deber jurídico es una situación jurídica de desventaja activa, en tanto que, por un lado, subordina un interés -el del sujeto gravado con el mismo-; y, por el otro, requiere del despliegue de un comportamiento para que su contenido se desarrolle.

Ahora bien, a pesar de que esta categorización del deber jurídico no ha sido puesto en tela de juicio, la doctrina ha debatido arduamente sobre la esencia del deber jurídico. De las teorías elaboradas, dos merecen ser rescatadas: la teoría formal y la teoría de la sanción.

\subsection{Teoría formal}

La teoría formal fue expuesta por la doctrina italiana, fundamentalmente por los autores que se afiliaron a las teorías «objetivas" sobre la obligación. ${ }^{15}$

Según Giovanni Pacchioni ${ }^{16}$, uno de los más autorizados exponentes de la teoría bajo examen, el deber jurídico no era sino el estado de presión psicológica en el que una persona se encontraba por el solo hecho de existir una norma jurídica que le imponía la «necesidad" de efectuar cierta conducta. Para que ese deber existiese no era imprescindible, según este autor, la presencia de una sanción aplicable ante su

15 Aunque con diferencias, las teorías objetivas de la obligación son aquellas que consideran que el objeto del derecho del acreedor no es la prestación a cargo del deudor. Estas teorías, largamente superadas desde hace muchos años, son las siguientes: (i) la teoría realista; (ii) la teoría del deber libre o de la carga; (iii) la teoría del débito y la responsabilidad; y, (iv) la teoría del bien debido.

16 Giovanni Pacchioni, Diritto Civile Italiano, Padova, Casa Editrice Dott. A. Milani, 1937, parte prima, volume primo, pp. 15 y 16. 
eventual incumplimiento. Lo fundamental, a fin de determinar la presencia de un deber jurídico, era que una norma jurídica, interpretando la conciencia pública en relación a las diversas necesidades de convivencia social y política, impusiese la «necesidad» de efectuar una conducta determinada. Que con tal propósito la norma acompañase a semejante "necesidad" alguna "sanción", era algo que únicamente influía en la observancia práctica de tal deber, más no en su propia configuración. ${ }^{17}$

En un sentido un tanto diverso, pero coincidente en lo concerniente a la irrelevancia de la sanción en la estructura del deber jurídico, se pronunciaron Calogero Gangi y Emilio Betti.

Para el primero, el deber jurídico era la necesidad, normativamente instaurada, de adoptar cierta conducta. La inexistencia de una sanción no enervaba el carácter "jurídico" de tal necesidad si es que ésta, de algún modo, era reconocida por el ordenamiento jurídico mediante algún efecto. En tal sentido, típico ejemplo de deber jurídico sin sanción lo constituía la obligación natural, ya que, a pesar de que su incumplimiento no acarreaba consecuencia "desfavorable» alguna para el infractor, aquella adquiría, en tanto necesidad, la «juridicidad" requerida (para devenir en deber jurídico) al reconocérsele el efecto de la solutio retentio. ${ }^{18}$.

Para el segundo, el deber jurídico, que entraba en la categoría genérica de exigencia de conducta futura, no necesitaba estar acompañado por algún tipo de sanción («responsabilidad») aplicable ante su incumplimiento. Para que un deber cualquiera adquiriese la impronta de la "juridicidad" no requería sino tener alguna clase de reconocimiento por parte del ordenamiento jurídico. Así, por ejemplo, la obligación natural, que constituía una exigencia para efectuar cierta conducta en el futuro, adquiría el carácter de deber jurídico con el simple reconocimiento ex post facto por el Derecho, sin necesidad de que el mismo (el Derecho) haya previsto alguna sanción para el caso de su incumplimiento. ${ }^{19}$

17 Giovanni Pacchioni, Il Concetto dell'Obbligazione, Rivista del Diritto Commerciale $e$ del Diritto Generale delle Obligazioni, Milano, Casa Editrice Francesco Vallardi, 1924, vol. XXII, parte prima, p. 224.

18 Calogero Gangi, Debito e Responsabilità nel Diritto Nostro Vigente, Rivista di Diritto Civile, Casa Editrice Dottor Antonio Milani, Milano, 1927, anno XIX, parte prima, p. 529. 19 Emilio Betti, Teoría General de las Obligaciones, traducción de José Luis de los Mozos, Madrid, Editorial Revista de Derecho Privado, 1969, tomo I, p. 274. 
De las posiciones adoptadas por estos autores queda claro que para la teoría formal, el deber jurídico no era más que una simple necesidad de actuación normativamente reconocida o, mejor, tipificada. La presencia o ausencia de una sanción -o reacción- ante el incumplimiento era algo absolutamente irrelevante. Lo único que interesaba era constatar la existencia de una orden normativamente recogida. ${ }^{20}$

\subsection{Teoría de la sanción}

La teoría de la sanción fue expuesta, principalmente, por Hans Kelsen y todos los que siguieron los postulados de la Teoría Pura del Derecho.

Según Kelsen ${ }^{21}$, para inducir a los individuos a conducirse en cierta manera, el Derecho no hacía otra cosa que ligar una sanción (que podía asumir la forma de la pena o de la ejecución forzada) a la conducta contraria. En consecuencia, la conducta cuya verificación era "condición» para la aplicación de la sanción establecida constituía una conducta prohibida, en tanto que la conducta cuya realización evitaba la aplicación de dicha sanción constituía una conducta prescrita.

Ahora bien, para este autor, el deber jurídico no era sino aquella conducta prescrita a la que se le acompañaba una sanción para el caso de incumplimiento. ${ }^{22}$ Si faltaba dicha sanción, la conducta prescrita no constituía un verdadero deber jurídico, sino tan sólo un deseo del legislador, carente sin embargo de toda relevancia jurídica. ${ }^{23}$

La razón por la cual todo deber jurídico tenía que estar acompañado de una sanción, radicaba en opinión de Kelsen, en la propia característica del Derecho como «técnica social de control». En efecto, según este autor, aquello que caracterizaba al Derecho frente a la moral, la costumbre, la religión y cualquier otra forma de control social, era la

20 Además de los autores citados, de una u otra manera se afilian a esta teoría: Alfredo Rocco, Studi sulla Teoria Generale del Fallimento, Rivista del Diritto Commerciale e del Diritto Generale delle Obligazioni, Milano, Casa Editrice Francesco Vallardi, 1910, vol. VIII, parte prima, pp. 678 y ss.; Alberto Trabucchi, Istituzioni di Diritto Privato, Padova, Cedam, 1962, p. 521; María Elena Diniz, Curso de Direito Brasilero. Teoria Geral das Obrigacoes, Sao Paulo, Editora Saraiva, 1996, p. 77.

21 Hans Kelsen, Teoría Pura del Derecho, traducido por Moisés Nilve, Buenos Aires, Editorial Universitaria de Buenos Aires, 1977, p. 76.

22 Hans Kelsen, op. cit., pp. 79 y 80.

23 Hans Kelsen, op. cit., p. 77. 
coactividad de sus preceptos; esto es, la posibilidad de hacerlos respetar utilizando la fuerza. ${ }^{24}$ En tal sentido, si se predicaba respecto de una conducta prescrita el atributo de la juridicidad, era imprescindible que la misma no pudiese ser inobservada sin una sanción de por medio; pues, de lo contrario, la norma que impusiese tal conducta no sería por faltarle la coactividad- jurídica. ${ }^{25}$

Que la presencia de la sanción fuese absolutamente necesaria para determinar la existencia del deber jurídico no implicaba, sin embargo, que aquella tuviera que incidir sobre el sujeto gravado con dicho deber. En efecto, según Kelsen, era perfectamente admisible que alguien distinto del que debía realizar la conducta prescrita tuviese, en tanto destinatario de la sanción, la calidad de responsable -por el deber ajeno-. ${ }^{26}$ Lo fundamental era, en consecuencia, que exista una prescripción y una sanción a ella vinculada por la norma.

Una vez aceptada la idea de que sólo existía deber jurídico cuando normativamente se preveía una sanción ante su incumplimiento, la doctrina se dividió en lo referente al concepto mismo de sanción. Así, para una primera corriente de opinión, únicamente existía sanción si la violación del deber determinaba la imposición de una nueva situación jurídica que, siendo más gravosa, denotara el odio o reproche a la actitud omisiva del sujeto transgresor. En este sentido, Brunetti, por ejemplo, indicaba que sólo se estaba ante un verdadero deber jurídico si es que la sanción aplicable ante su violación constituía una "pena», esto es, una acción o situación más gravosa que implique un "odio" o "repugnancia" a la desobediencia. Si faltaba este último carácter y la mayor "desventaja" del infractor respondía a motivos (o fines) distintos del mero y simple reproche, no existía "pena" y, por lo tanto, no se estaba ante una auténtica sanción. ${ }^{27}$

Para una segunda corriente de opinión, la sanción no necesariamente tenía que ser una acción o situación impuesta en "odio" o "repugnancia", ya que lo que importaba era que la misma, repercutiendo en

24 Hans Kelsen, op. cit., pp. 72 a 74.

25 Hans Kelsen, op. cit., pp. 77, 79 y 80.

26 Hans Kelsen, op. cit., pp. 91 a 93.

27 Giovanni Brunetti, Il Diritto del Creditore, Rivista del Diritto Commerciale e del Diritto Generale delle Obbligazioni, Milano, Casa Editrice Francesco Vallardi, 1916, vol. XIV, parte prima, p. 288. 
el sujeto transgresor del deber, creara la necesidad de enervar las consecuencias negativas de la violación. ${ }^{28}$

En consecuencia, y más allá de las diferencias en torno al concepto de sanción, para esta teoría la existencia del deber jurídico depende de la presencia de una reacción negativa prevista por el ordenamiento para cuando el comportamiento ordenado no sea efectivamente realizado.

\section{Reconstrucción de la figura}

\subsection{El deber jurídico no es un fin en sí mismo}

Como ya se indicó, el fin del Derecho (objetivo) no es otro que el logro de la justa y pacífica convivencia de los seres humanos. Para conseguir este anhelo, el Derecho otorga a los sujetos diversas facultades de obrar a fin de que éstos realicen sus propios intereses. Es obvio, sin embargo, que, con miras a la "consecución" de la finalidad mencionada, de nada serviría que se concediese a todos los sujetos facultades de obrar sobre todos los bienes que existen en la naturaleza pues, tal como ha sido relievado, ${ }^{29}$ se crearía así la anarquía y sólo el predominio del más fuerte determinaría el concreto y efectivo goce de dichos bienes. En este sentido, resulta necesario que sobre cada bien únicamente exista un derecho subjetivo (o, más genéricamente, una situación jurídica subjetiva de ventaja)..$^{30}$

Ahora bien, para que, en realidad, sobre cada bien exista un único derecho subjetivo, resulta necesario que a los sujetos que no ostentan

28 En tal sentido: Luis Recasens Siches, Introducción al Estudio del Derecho, México, Editorial Porrúa S.A., 1977, p. 130.

29 Oscar Morineau, Il Concetto di Diritto Soggetivo, JUS. Rivista di Scienze Giuridiche, Milano, Università del Sacro Cuore, 1954, Año V, p. 160.

30 Lo que en realidad se quiere decir con esto no es tanto que dos derechos subjetivos no puedan coexistir sobre un único bien, como que el comportamiento que autorizan -en tanto coincidentes en todo o en parte- no pueda ser desplegados al mismo tiempo, ya que de este modo se crearía una situación de "conflicto". Esto, por ejemplo, se ve claramente en el caso de la propiedad y el usufructo. De esta manera, estos derechos coexisten sobre un mismo bien, hecho que sin embargo no ocasiona situación conflictual alguna, desde que el ordenamiento permite dicha coexistencia únicamente al amparo de la prohibición legal de que uno de ellos (el de propiedad) sea ejercido en todo o en parte (sobre el particular ver: Domenico Barbero, L'Usufrutto e I Diritti Affini, Milano, Dott. A. Giuffrè Editore, 1952, p. 30 y ss.). 
la titularidad de éste les sea impuesta la necesidad o el deber de no interferir con el "goce» que dicho derecho le puede procurar a su titular. En efecto, si haciendo caso omiso a esta necesidad, cualquier sujeto pudiera actuar libremente, o sea sin ninguna consecuencia jurídica desfavorable para él, sobre cualquier bien, perturbando o impidiendo de este modo el despliegue de las facultades contenidas en el supuesto derecho que recae sobre el mismo, su situación jurídica sería exactamente igual a la del sujeto que ostenta el referido derecho, pues ambos podrían aprovecharse del bien, lo cual es incompatible con la idea misma de derecho subjetivo, en tanto que éste no puede existir cuando, al estar todos facultados a obrar sobre el mismo objeto, la satisfacción del interés dependa, en realidad, del resultado de la pugna que en los hechos se lleve a cabo. Para que esto no suceda y se tenga en consecuencia un verdadero derecho sobre algo, resulta necesario que cada vez que se conceda una facultad de obrar, se establezca al mismo tiempo un «correlativo" deber jurídico que, gravando a todo tercero, imposibilite jurídicamente claro está- la realización de toda conducta que en algún modo pueda perturbar o impedir la efectivización de aquella facultad y, por ende, la satisfacción o realización del interés que le sirve de presupuesto. ${ }^{31}$ En este sentido, se puede válidamente afirmar que el deber jurídico resulta ser un "medio de protección» del cual el ordenamiento jurídico se sirve para garantizar la existencia de una situación -jurídicaque ha considerado «relevante». ${ }^{32}$

31 En tal sentido: Giovanni Miele, Potere, Diritto Soggetivo e Interesse, Rivista del Diritto Commerciale e del Diritto Generale delle Obbligazioni, Milano, Casa Fditrice Francesco Vallardi, 1944, vol. XLII, parte prima, p. 115; Luigi Ferri, La Autonomía Privada, traducción de Luis Sancho Mendizabal, Madrid, Editorial Revista de Derecho Privado, 1969, p. 247; Giorgio Del Vecchio, Filosofía del Derecho, traducido por Luis Legaz y Lacambra, Bosch Casa Editora S.A., 1980, p. 392; Rosario Nicolò, op. cit., p. 131; Enrico Véscovi, Il Concetto del Diritto Subbiettivo e la Realta Contemporanea, Rivista Internazionale di Filosofia del Diritto, 1961, anno XXXVIII, serie III, fascicolo V, p. 403; Eduardo García Maynez, Derecho Subjetivo, Enciclopedia Jurídica Omeba, Editorial Bibliográfica Argentina, Buenos Aires, s/f, tomo VIII, p. 274; José Alberto Zambrano, Noción de Obligación, Libro Homenaje a la Memoria de Lorenzo Herrera Mendoza, Caracas, Universidad Central de Venezuela, 1970, tomo I, p. 627.

32 Cuando el deber jurídico es un medio de protección sus destinatarios son todos aquellos que no siendo titulares de un derecho -o de una situación jurídica subjetiva de ventaja- pueden, de facto, perturbar o impedir la satisfacción del interés presupuesto en el mismo. En tal sentido, este deber no hace otra cosa que colocar a los terceros en la necesidad de no interrumpir o impedir el ejercicio del derecho ajeno y, consecuentemęnte, la satisfacción del interés que dicho derecho presupone. Es necesario señalar, como lo ha demostrado la más 
Que el deber jurídico sea medio de protección no implica, sin embargo, que sea solamente eso. En efecto, atendiendo a la circunstancia de que el derecho subjetivo no se agota en una facultad directa sobre un bien, sino que también puede adoptar la forma de una facultad -por así llamarla- indirecta sobre el mismo, al autorizar su obtención a través de una exigencia dirigida hacia otro individuo, resulta necesario que, además del referido deber (o sea, del general), exista otro de carácter específico que, correlativamente ligado a aquél (esto es, al derecho subjetivo), no convierta en vana la pretensión concedida. Aquí se requiere, en consecuencia, además de la entidad externa que cree las condiciones necesarias para ejercer el propio derecho, la presencia de una situación de deber (o necesidad), que, sobre la base de la primera, esté llamada a realizar el contenido de la facultad indirecta hasta llegar a convertirla en una facultad directa. ${ }^{33}$ En este caso, es claro que el deber jurídico asume la calidad de "medio de realización» de una situación jurídica considerada como relevante por el Derecho. ${ }^{34}$

atenta doctrina, que el deber de protección ampara tanto a los «derechos absolutos" como a los "derechos relativos». En tal sentido, su violación puede afectar, por ejemplo, al propietario de una cosa cualquiera (piénsese en los daños derivados de su destrucción total o parcial) o al acreedor de cierta prestación (piénsese en los daños derivados de la inducción a su incumplimiento). Ante la efectiva transgresión de este deber el ordenamiento otorga un mecanismo genérico de tutela que consiste en la posibilidad de exigir una reparación económica. Este mecanismo de tutela se actúa siempre en sede extracontractual, de modo tal que el titular del derecho que se sienta lesionado por la referida transgresión debe probar (i) la existencia del daño; (ii) la existencia de una relación de causalidad entre la actuación del tercero y el daño; (iii) la existencia de un factor atributivo de responsabilidad; y, (iv) la inaplicación del algún factor de exclusión de responsabilidad (sobre la tutela aquilina de los uderechos personales" ver: Francesco Donato Busnelli, La Lesione del Credito da Parte di Terzi, Milano, Dott. A. Giuffrè Editore, 1963 , p. 23 y ss.).

33 La idea es, fundamentalmente, de Rosario Nicolò (ver: op. cit., pp. 139 y 142 a 145). La siguen, entre otros: Salvatore Satta, citado por Salvatore Pugliatti, Il Trasferimento delle Situazioni Soggetive, Milano, Dott. A. Giuffrè Editore, 1941, p. 49; Ismael Peidró Pastor, Lino y Rodríguez-Arias Bustamante, op. cit., p. 285.

34 Cuando el deber jurídico es un medio de realización su destinatario es aquel que está llamado a satisfacer el interés presupuesto en el derecho -o en la situación jurídica subjetiva de ventaja- conectado. Como se podrá advertir, a diferencia del deber de protección, el deber de realización no consiste en no perturbar o impedir el ejercicio del derecho ajeno sino más bien en satisfacer el interés que el mismo presupone. En tal sentido, es evidente que este deber sólo ampara a los "derechos personales", esto es, a los que se resuelven en la posibilidad de exigir a alguien la realización de determinada conducta. Su violación, por ende, no puede afectar al titular de un derecho cualquiera sino solamente al titular de una pretensión. Ante la efectiva transgresión de este deber, el ordenamiento concede dos mecanismos genéricos de tutela, a 
Pero el deber jurídico, qué duda cabe, no se explica de manera íntegra en función a la existencia del derecho subjetivo -o de la situación jurídica subjetiva de ventaja-. En efecto, hay supuestos en los cuales el deber jurídico no tiene frente a sí mismo un derecho subjetivo cuya existencia garantizar $y$, en algunos casos, cuya realización provocar. ${ }^{35}$ ¿Implicará esto que la función instrumental que sobre esta clase de deber se ha ido perfilando se pierde aquí? En modo alguno. Cuando el deber jurídico no aparece "relacionado" con un derecho subjetivo, su función instrumental, contra lo que pudiera parecer, no desaparece. Sostener lo contrario implicaría tener por verdadero que el derecho subjetivo constituye el único fenómeno que, a través del deber jurídico, el ordenamiento busca proteger o realizar. Y esto, evidentemente, no es así. La existencia de una serie de situaciones jurídicas -distintas al derecho subjetivo- y no jurídicas cuya "configuración» o «conservación" el ordenamiento jurídico considera deseable es, en realidad, algo de lo que no puede dudarse. Por ello, la presencia de un deber jurídico sin un correlativo derecho subjetivo en modo alguno autoriza a concluir que aquí tal deber pierde su calidad de "medio» o «instrumento", para convertirse en un fin en sí mismo. Lo que en tal caso ocurre es simplemente que dicho deber está "protegiendo" o "realizando" una situación distinta del derecho subjetivo, que, al igual que éste, ha sido considerada "relevante» por el ordenamiento jurídico. ${ }^{36}$

En consecuencia, podemos afirmar, a la luz de lo expuesto, que el deber jurídico no es sino aquella herramienta que, impuesta como necesidad de realizar cierto comportamiento, el Derecho utiliza para

saber: la ejecución forzada y la reparación económica. Estos mecanismos de tutela no se actúan en sede extracontractual sino en la mal denominada sede "contractual». Ahora bien, como quiera que sin el deber de protección ningún derecho puede preciarse de ser tal, es obvio que el deber de realización termina coexistiendo con aquél. Sin embargo, es bueno anotar que mientras el deber de realización está funcionalmente conectado con el derecho "relativo", el deber de protección está conectado con una situación jurídica subjetiva de ventaja innominada que el ordenamiento le otorga al titular de dicho derecho.

35 Piénsese, por ejemplo, en el caso del deber impuesto por el artículo $20^{\circ}$ de la Ley General de Salud, según el cual toda persona debe participar en el mejoramiento de la cultura sanitaria de su comunidad. Aquí, tal deber ni garantizan la existencia de una situación jurídica subjetiva de ventaja ni realiza el contenido de la misma.

36 Conforme: Romano Santi, citado por Lino Rodríguez-Arias Bustamante, El concepto de obligación con especial referencia al deber jurídico en el código panameño y en otros ordenamientos de la especie, La Justicia, México, 1969, tomo XXVIII, número 472, p. 42. 
garantizar la permanencia y, eventualmente, la realización de ciertas situaciones jurídicas; o la permanencia o consecución de ciertas situaciones no-jurídicas a las que considera "deseables». ${ }^{37}$

\subsection{El deber jurídico es necesitas agendi}

El deber jurídico no es, como se ha pretendido, un estado de «presión psicológica» generado por la norma jurídica en el sujeto gravado con el mismo (deber), pues, aparte de que tal concepción presupone un efecto subjetivo -presión psicológica- que no siempre se presenta, de esta manera se termina por excluir a las personas jurídicas como sujetos pasivos de dicho deber, en tanto que de éstas no puede predicarse la existencia de estado psicológico alguno.

En realidad, si de algo no se puede dudar es de que el deber jurídico se resuelve, en todos los casos, en una situación de «necesidad» que impulsa al sujeto a realizar determinado comportamiento como consecuencia de ser el destinatario de una orden o mandato. ${ }^{38}$ Esta situación de «necesidad» es opuesta a aquella de "libertad" en la que el sujeto gravado con el deber jurídico- se encontraría en caso de no existir la orden.

37 En tal sentido, Andreas Von Thur, Derecho Civil. Teoría General del Derecho Civil Alemán, traducido por Tito Ravà, Buenos Aires, Editorial Depalma, 1946, tomo I, vol. I, p. 124; Francesco Saverio Azzariti; Giovanni Martínez; y Giuseppe Azzaritti, Diritto Civile Italiano, Padova, Cedam, 1943, tomo I, pp. 8 y 9; Mario Rotondi, Istituzioni di Diritto Privato, Milano, Libreria Aurelio Paraninfo, 1965, p. 95; Oscar Morineau, op. cit.

38 En este sentido: Andreas Von Thur, Tratado de Obligaciones, traducción de W. Roces, Madrid, Editorial REUS S.A., 1934, tomo I, p. 4; Hans Kelsen, op. cit., p. 121; Domenico Barbero, Sistema de Derecho Privado, traducido por Santiago Sentís Melendo, Buenos Aires, Editorial Jurídica Europa-América, 1967, tomo I, p. 157; Pietro Trimarchi, op. cit., pp. 56 y 57; Paolo Zatti y Vittorio Colussi, op. cit., pp. 64 y 65; Rosario Nicolò, op. cit., p. 130; Paulo Dourado de Gusmao, Introduçao ao Estudio do Direito, Rio de Janeiro, Companhia Editora Forense, 1998, p. 256; Lino Rodriguez-Arias Bustamante, y Ismael Peidró Pastor, Teoría del Deber Jurídico y del Derecho Subjetivo, Revista General de Legislación y Jurisprudencia, Segunda Época, tomo XV, año XCIII, número 3, p. 267; Federido Puig Peña, Tratado de Derecho Civil Español, Madrid, Editorial Revista de Derecho Privado, 1974, tomo IV, vol. I, p. 24; María Ángeles Egusquiza, La Configuración Jurídica de las Obligaciones Negativas, Barcelona, José M. Bosch Editor, S.A., 1990, p. 13; Luis Diez-Picazo, Fundamentos de Derecho Civil Patrimonial, Madrid, Editorial Civitas, 1993, tomo Il, p. 48; Darío Duque Pérez, La Obligación Civil, Estudios de Derecho, Medellín, Facultad de Derecho y Ciencias Políticas de Antioquia, 1972, vol. XXXI, número 82, p. 256. 
Ahora bien, es preciso entender el asunto correctamente. Por situación de "necesidad" no ha de interpretarse una de carácter físico o material (necesidad absoluta), sino tan sólo una de carácter moral o deontológica (necesidad relativa). En efecto, el deber jurídico no ser puede identificado con una situación que constriña física o materialmente al individuo. El ámbito en el que «juega» presupone, necesariamente, la «libertad» -en su más amplia acepción- de cumplir o no la orden o mandato del cual deriva. El deber jurídico, al estar "encasillado" en el plano no de «lo que es», sino de lo que «se espera que sea», implica la posibilidad de que «lo esperado" no llegue a materializarse. Es por ello que se sostiene con insistencia que sólo aquellas situaciones de "necesidad" que pueden ser "transgredidas" por el propio sujeto gravado con las mismas son las que pueden constituir deberes jurídicos. ${ }^{39}$

Que el deber jurídico sea una «necesidad» de orden moral no quiere decir, sin embargo, que no sea distinto del llamado "deber moral", pues mientras aquel se instaura en el plano positivo, este último lo hace en el plano extrapositivo. Y la diferencia del distinto plano en el que cada uno se inserta se traduce, finalmente, en las disímiles consecuencias que su transgresión provoca. Así, mientras el incumplimiento del deber jurídico origina consecuencias jurídicas consistentes en el nacimiento de nuevas situaciones (jurídicas subjetivas) que posibilitan obtener su cumplimiento "forzado" o, en todo caso, la eliminación de los efectos negativos que la inejecución ha provocado, el incumplimiento del deber moral no origina consecuencia jurídica alguna, de manera tal que la realidad jurídica no se ve modificada por el hecho de su violación. ${ }^{40}$

Ahora bien, así delimitada la esencia del deber jurídico, preciso es indicar que, como quiera que la actuación del mismo se resuelve en el despliegue de una actividad humana, aquello que tiene que realizarse (conducta prescrita) necesita poder ser cumplido, esto es, ejecutado, por el sujeto sobre el cual pesa el deber. Si no fuese así, es decir, si el

39 En ese sentido: Mario Allara, Le Nozioni Fondamentali del Diritto Civile, Torino, Giappichelli-Editore, 1949, vol. I, p. 265; Giuseppe Grosso, Las Obligaciones. Contenido y Requisitos de la Prestación, traducido por Fernando Hinestrosa, Bogotá, Universidad Externado de Colombia, 1981, p. 131.

40 Conformes: Andreas Von Thur, Andreas: Tratado [...], tomo I, p. 4; Federico Puig Peña, op. cit., tomo IV, vol. I, p. 24. 
comportamiento ordenado no pudiera ser realizado por el sujeto gravado con el deber, ningún sentido tendría hacer nacer en su cabeza una situación jurídica subjetiva -de desventaja-como esta; salvo que, con prescindencia de toda lógica y de algún criterio mínimo de justicia, se establezca, sin que interese la imposibilidad de cumplir, que se tiene ejecutar lo ordenado, bajo pena de hacer efectiva la sanción prevista (que, como se verá, está siempre presente). Como esto, sin embargo, no puede ser admitido, ha sido consagrado sino en todos los ordenamientos por lo menos en la mayoría de ellos, un principio según el cual el nacimiento y la subsistencia del deber jurídico depende de la posibilidad que se tenga para cumplirlo. En nuestro caso, el mencionado principio se encuentra recogido en varias normas del Código Civil, como son las contenidas en los artículos $219^{\circ}, 1138^{\circ}, 1154^{\circ}, 1155^{\circ}$, $1156^{\circ}, 1166^{\circ}, 1431^{\circ}, 1432^{\circ}$, entre otros.

Por lo tanto, podemos afirmar, con Betti ${ }^{41}$, que deber jurídico únicamente se tiene cuando aquel que ha sido gravado con el mismo cuenta con el «poder» de hecho para cumplirlo. Si esto no es así, dicho deber no habrá nacido -o se habrá extinguido de ser sobreviniente la imposibilidad de cumplirlo- ${ }^{42}$.

41 Emilio Betti, Dovere Giuridico, Enciclopedia del Diritto, Giuffrè Editore, 1965, tomo XIV, pp. 56 y 57.

42 El requisito de la posibilidad física encuentra su origen en el Derecho romano, donde se sancionaba con nulidad a aquella obligación que, desde un comienzo, no era susceptible de cumplimiento (impossibilium nulla obligatio est). Para comprender los alcances de este requisito, que ha sido estudiado como una cualidad exigida a la prestación, la doctrina ha diferenciado entre una imposibilidad absoluta y otra relativa, por un lado; y una imposibilidad objetiva y otra subjetiva, por el otro. La imposibilidad «absoluta» constituiría un impedimento que no puede ser vencido por la fuerza humana, en tanto que la imposibilidad "relativa» constituiría un impedimento que sólo puede ser vencido empleando un esfuerzo superior al ordinario. Por su parte, la imposibilidad «objetiva» constituiría un impedimento que determina que nadie pueda ejecutar la prestación, mientras que la imposibilidad «subjetiva» constituiría un impedimento que determina que el deudor no pueda ejecutar la prestación. Bien visto el asunto, sin embargo, la imposibilidad "absoluta" y la "objetiva" son equiparables, motivo por el cual tesulta ocioso distinguirlas. A su vez, la imposibilidad "relativa" no presenta mayor relevancia, en tanto que el "esfuerzo superior al ordinario» no tiene como objeto de referencia la situación del deudor, que es la que interesa. En realidad, la única distinción que posee valor es aquella que diferencia entre una imposibilidad que afecta a todos y otra que afecta al deudor, pues solamente en este último caso es pertinente la pregunta de si se cumple o no el requisito de la posibilidad física. Enfocado de esta manera el problema, se debe señalar que, de conformidad con una difundida corriente de opinión, tributaria del Derecho romano, basta con que alguien pueda efectuar la prestación para que se considere que ésta es físicamente posible, sin que 


\title{
4.3 El deber jurídico requiere de la presencia -externa- de la sanción
}

\author{
Que el deber jurídico sea una situación de necesidad no implica, em- \\ pero, que en lo que ha de constituir su exacta noción no haya un lugar \\ para la sanción. En efecto, así como en sede de derecho subjetivo se \\ encuentran entidades externas que son determinantes para arribar a
}

interese si el deudor se encuentra o no en condiciones de cumplir la obligación. La razón por la cual se sostiene esto es la siguiente: si el deudor no está en aptitud de ejecutar la prestación no importa, pues si bien no se le podrá pedir la satisfacción in natura del interés del acreedor, se le podrá exigir en cambio el id quod interest, esto es, una indemnización que satisfaga por "equivalente» dicho interés. Contrariando esta forma de entender el asunto, otra corriente de opinión, notoriamente menos seguida que la primera, considera que la prestación es físicamente posible sólo cuando el deudor está en aptitud de ejecutarla. La razón por la cual se sostiene esto es bastante sencilla: tanto la imposibilidad absoluta como la relativa determinan que la conducta in obligatione no pueda ser verificada en los términos previstos. De las dos posiciones examinadas, ¿cuál es la correcta? La respuesta, en realidad, depende del interés que se trate de privilegiar. En efecto, si lo que se quiere es tutelar el interés que el acreedor tiene en que los impedimentos particulares que afectan al deudor no influyan en el surgimiento del derecho de crédito, habrá que acoger los postulados de la primera posición. Pero, si por el contrario, lo que se quiere es tutelar el interés que el deudor tiene en no ser gravado con un deber que no está en condiciones de cumplir, habrá que acoger los postulados de la segunda posición. La alternativa planteada ha de ser, pues, resuelta única y exclusivamente sobre la base de una opción de política legislativa. Se equivocan, por eso, los defensores de la primera posición cuando intentan demostrar el valor intrínseco de la misma, afirmando para ello que la imposibilidad del deudor de ejecutar la prestación no debe determinar la inexistencia de la obligación, en tanto que si bien ésta no se ejecutará in natura, podrá en cambio ejecutarse por "equivalente». Con este razonamiento, los autores que adoptan la posición mencionada no se percatan que si la causa de la irrelevancia de la imposibilidad «subjetiva» es que el id quod interest todavía va a poder ser prestado, habría que tener por intrascendente, también, a la imposibilidad "objetiva", pues igualmente el id quod interest va a poder ser prestado en caso que la misma se presente. Ahora bien, una vez aclarado que ninguna de las posturas indicadas es intrínsecamente incorrecta, cabe advertir que si la ley no establece cómo ha de entenderse el requisito de la posibilidad física (de la prestación), la posición que se adopte debe ser aquella que guarde coherencia con el régimen de responsabilidad que haya sido consagrado positivamente. En efecto, no puede abogarse, por ejemplo, por una posición objetiva en torno al referido requisito cuando el régimen de responsabilidad descansa en un factor subjetivo apreciable in concreto. Así es, si un ordenamiento jurídico consagra a la ausencia de culpa in concreto como eximente de responsabilidad, el acreedor no podría pretender el pago de una indemnización por incumplimiento originado en imposibilidad subjetiva pues ésta, de por sí, excluye a la culpa in concreto. Entonces, si en un contexto como este un sujeto se obliga a efectuar determinada prestación en favor de otro y resulta que eso es subjetivamente imposible $a b$ origine, tendremos que aquél necesariamente incurrirá en incumplimiento. Pero como tal incumplimiento no obedecerá a culpa del obligado, éste, por aplicación del factor de exoneración de responsabilidad ya mencionado, no tendrá que prestar el id quod interest. Y si esto es así, es decir, si el acreedor del individuo afectado por la imposibilidad no puede pretender 
una correcta noción del instituto, ${ }^{43}$ aquí también hallamos una entidad que, siendo diferente del deber mismo, viene a influir desde fuera en su propia naturaleza. Dicha entidad es, como se ha adelantado, la sanción.

Si se considera que el deber jurídico proviene de una orden o mandato, no es admisible que ante su transgresión no exista alguna consecuencia en el plano jurídico. Y no es admisible por esto: «obligatoriedad" de una conducta e inmunidad de reacciones en caso de conducta contraria -es decir esencialmente, libertad de tener una conducta disconforme- son, como se ha dicho, ${ }^{44}$ términos contradictorios. En efecto, si se toma en consideración que en su acepción más elemental, el deber jurídico es la «necesidad» impuesta por el ordenamiento jurídico de efectuar cierto comportamiento, no puede sino concluirse que, ante la falta de actuación de lo «ordenado», necesariamente tiene que existir

la ejecución de la prestación ni puede reclamar el pago de una indemnización, ¿para qué debería nacer la obligación? La respuesta a la pregunta formulada es obvia: no hay razón alguna para que surja una relación inservible. En estos casos (o sea, cuando exista un factor subjetivo de exoneración de responsabilidad evaluado in concreto), por tanto, la imposibilidad "relativa" debería bastar para considerar no cumplido al requisito estudiado. Se puede concluir, por tanto, que cuando la ley calla, el carácter objetivo o subjetivo del régimen de responsabilidad será el que determine la naturaleza subjetiva u objetiva del requisito de la posibilidad física de la prestación. Ahora bien, sea como fuere -esto es, que el requisito de la posibilidad física (de la prestación) se considere cumplido (i) si el deudor está en aptitud de ejecutarla; o, (ii) si algún individuo está en condiciones de realizarla- es necesario advertir que aquello que llamamos prestación tiene que constituir un fenómeno que derive de manera directa del comportamiento del hombre. En otras palabras, tanto el "comportamiento adecuado" en el cual consiste la prestación subjetiva (objeto de la obligación de medios) como el "comportamiento con resultado esperado" en el cual consiste la prestación objetiva (objeto de la obligación de resultado), deben poder ser alcanzados por el hombre. Si ni el deudor ni algún tercero dependiendo de la amplitud que en concreto asuma el requisito bajo análisis (posibilidad subjetiva u objetiva)- pueden lograr una "conducta adecuada", quiere decir entonces que físicamente no es factible cumplir la obligación de medios. Del mismo modo, si el "resultado esperadon no puede ser alcanzado por el deudor o por algún tercero -otra vez, dependiendo de la amplitud que en concreto asuma el requisito bajo examen-, significa entonces que físicamente no es factible cumplir la obligación de resultado.

43 Sobre el particular se puede consultar: Freddy Escobar, El Derecho Subjetivo. Consideraciones en torno a su esencia y estructura, Ius Et Veritas. Revista Editada por Estudiantes de la Facultad de Derecho de la Pontificia Universidad Católica del Perú, año IX, número 16, p. $280 \mathrm{y}$ ss.

44 Aurelio Candian, Instituciones de Derecho Privado, traducido por Blanca P. L. de Caballero, México D. F., Unión Tipográfica Hispano Americana, 1961, p. 7; Giorgio Oppo, citado por Giovanna Visinti, Obbligazioni Naturali, Rivista di Diritto Civile, Padova, Casa Editrice Dott. Antonio Milani, 1962, anno VIII, parte seconda, p. 48. 
algún tipo de reacción -negativa- por parte de tal ordenamiento frente al sujeto que omite actuar uno de sus preceptos. Una actitud de simple "indiferencia» por parte de este último eliminaría, en verdad, cualquier idea de deber jurídico; pues el sujeto gravado con la pretendida «necesidad» estaría en la misma situación jurídica en la que se encuentra aquel a quien no se dirige la norma jurídica que la impone (a la «necesidad»). En este sentido, resulta imprescindible, a los fines de tener por "deber jurídico" determinado comportamiento impuesto, que la inactuación del mismo provoque una reacción por parte del ordenamiento, de modo tal que el sujeto que omite actuar se vea afectado por una nueva situación jurídica que esté dirigida a eliminar las consecuencias negativas de su «inconducta». En otras palabras, es necesaria la presencia de una sanción. ${ }^{45}$

A esta conclusión no puede oponerse, ciertamente, el argumento según el cual, basta que se dé algún tipo de reconocimiento jurídico para que el deber que ha sido privado de sanción adquiera la impronta de la «juridicidad», pues el único ejemplo que demostraría esto no logra, en realidad, cumplir su cometido. Así, se afirma que la obligación natural $^{46}$ constituye un deber que, pese a estar desprovisto de sanción,

45 En tal sentido: Hans Kelsen, op. cit., pp. 79 y 80; Lodovico Barasi, La Teoria Generale delle Obbligazioni, Milano, Dott. A. Giuffrè Editore, 1963, vol. I, pp. 31 y 32; Luis Legaz Lacambra, Deber, Nueva Enciclopedia Jurídica, Barcelona, Francisco Seix Editor, 1954, tomo VI, p. 251; Luis Recasens Siches, op. cit., p. 130; Rubén Compagnucci de Caso, Obligación y Responsabilidad, Revista Notarial. Organo del Colegio de Escribanos de la Provincia de Buenos Aires, La Plata, 1980, número 853, p. 2108; José Roberto Vernego, Curso de Teoría General del Derecho, Buenos Aires, Depalma, 1985, pp. 205 y 206.

46 La "obligación natural" ha sido concebida como aquella cuyo "pago" no es posible exigir, mas sí retener, siempre y cuando el mismo haya sido efectuado de manera voluntaria por el "deudor». Al igual que muchos otros institutos, la "obligación natural» surgió en el Derecho Romano en el momento en que los pretores, advirtiendo la necesidad de integrar a los extranjeros a la vida económica de Roma, comenzaron a conceder cierta relevancia a la deuda surgida en el ius naturale y en el ius gentium (concretamente, aquellos permitieron que el acreedor de la misma pudiera retener la prestación voluntariamente ejecutada; paulatinamente, y de acuerdo a los casos, también permitieron la imputación del pago de una uobligación natural", la compensación de una "obligación natural» con una civil, la novación de una "obligación natural», etc.). Con el transcurso del tiempo, y por obra de un sector de la doctrina francesa clásica contrario a las ideas romanistas de Domat (Pothier, Radouant, Planiol, Ripert y Savatier), la "obligación natural" dejó de ser considerada como una deuda surgida en ordenamientos distintos del ius civile para pasar a ser considerada como una deuda moral o de conciencia. Felizmente, la atadura al Derecho Canónico y al iusnaturalismo llegó a su fin cuando la doctrina italiana (Oppo, Mori-Checcucci, Giorgianni), independizada ya de los 
resulta "jurídico", ya que el ordenamiento le reconoce el efecto de la solutio retentio. Con este razonamiento no se advierte, sin embargo, que semejante efecto en modo alguno resulta idóneo para demostrar que un deber carente de sanción es jurídico. De esta manera, si la retención de la prestación sólo se produce una vez que el deber ha sido cumplido y, por ende, una vez que ha quedado extinguido, no se entiende cómo el tinte de «juridicidad» que dicha retención implica pueda retrotraerse hasta antes de que se verifique en la realidad el hecho que le sirve de presupuesto de actuación. Para una mirada atenta, resulta evidente que la solutio retentio no puede hacerle adquirir ex post la «juridicidad" que le faltaba a este deber sin sanción. Y nótese que quien sostenga lo contrario, esto es, que la retención de la prestación hace adquirir «juridicidad" a ese deber, tendría que admitir necesariamente que el mismo, en tanto "jurídico», nace de su propio cumplimiento (hecho que determina su extinción), lo cual es evidentemente una contradictio in adiecto. ${ }^{47}$

Que la presencia de la sanción jurídica sea fundamental para determinar la existencia misma del deber jurídico tampoco puede contrade-

influjos franceses, comenzó a concebir a la "obligación natural" en términos de relación de hecho que adquiere relevancia para el Derecho solamente en el momento del cumplimiento. Actualmente, nadie se atreve a considerar a la "obligación natural" como verdadera obligación, desde que a la luz de los conceptos de derecho subjetivo y de deber jurídico, es absolutamente imposible reconducirla a la categoría de la relación jurídica. Que esto sea así no quiere decir, sin embargo, que esté permitido desconocer la trascendencia jurídica de esta figura, sustentada en la exclusión de la condictio indebiti; pues, como lo ha demostrado la doctrina más atenta, dicha exclusión no es más que una técnica utilizada por el legislador para reconocer en el "pago» de una "obligación natural a una especial causa de atribución patrimonial, similar, en cierto sentido, a la que informa los supuestos de adquisición originaria. En consecuencia, aunque no pre-exista un deber jurídico destinado a producir el efecto atributivo, la solutio retentio, que más que legitimar al accipiens a no restituir la prestación lo legitima a apropiarse de la misma, viene a demostrar, de manera incuestionable, que el "pago" voluntario de una "obligación natural" es, para el ordenamiento jurídico, una justa causa de adquisición; justa causa que explica porqué el desplazamiento patrimonial provocado por el tradens permanece firme (para un análisis cuidadoso del tema: Franco Carresi, L'obbligazione naturale nella più recente Letteratura guiridica italiana, Rivista Trimestrale di Diritto e Procedura Civile, Milano, Dott. A. Giuffrè Editore, 1948, anno II, p. 573 y ss.).

47 Magistralmente: Roberto De Ruggiero y Fulvio Maroi, Istituzioni di Diritto Privato, Milano, Casa Editrice Giuseppe Principato, 1947, vol. II, p. 8; Carmelo Scuto, Istituzioni di Diritto Privato, Napoli, Libreria Internazionale Teves di Leo Lupi, 1955, vol. I, p. 572; Francisco Bonet Ramón, Naturaleza Jurídica de la Obligación, Revista de Derecho Privado, Madrid, Editorial Revista de Derecho Privado, 1967, tomo LI, pp. 843 y 844. 
cirse con el argumento de que si esto es así, la necesaria «juridicidad» de la sanción también debería estar asegurada por la presencia de una otra y así de manera sucesiva ad infinitum, lo cual sería lógicamente inaceptable; ${ }^{48}$ pues, tal como lo ha notado Nicolò, ${ }^{49}$ existen ciertas sanciones que, como último estadío de una cadena, no son susceptibles de "transgresión", de donde se sigue que éstas no necesitan de otras sanciones que garanticen su «juridicidad». En efecto, si es que se piensa en todos aquellos estados de sujeción ${ }^{50}$ que afectan a los sujetos, fácilmente se comprenderá que ellos, al constituir situaciones de necesidad

48 La observación es de Vittorio Frosini, Diritto Soggetivo e Dovere Giuridico, Rivista di Diritto Civile, Padova, Cedam, 1961, anno VII, parte prima, pp. 127 y 128.

49 Rosario Nicolò, op. cit., p. 131.

50 El estado de sujeción es aquella situación en la que se encuentra el sujeto llamado a sufrir, en su esfera jurídica, las consecuencias del ejercicio de una situación opuesta. El que se coloca en una posición como esta no necesita prestar colaboración -actuada- alguna a fin de que el sujeto titular de la posición correlativa realice su interés, ya que al afectar su esfera jurídica a la decisión de éste, no hay lugar para que actúe. Así, por ejemplo, quien asume la posición de concedente, en el marco de un contrato de opción, no tiene que dar, hacer o no hacer, a fin de que el interés del optante se realice. Aquí, dado que dicho concedente afecta su esfera jurídica en favor de este último, al otorgarle la posibilidad de celebrar con su declaración el contrato definitivo, el resultado esperado por el titular de la situación de ventaja puede ser conseguido por él mismo, a través del ejercicio de la mencionada posibilidad. De la particular configuración de esta situación jurídica se deriva que el sujeto gravado con ella no pueda incumplitla. Así si dicho sujeto no tiene que obrar, es evidente que no es posible que él no "actúe» el contenido de la situación que lo afecta, de modo que origine un supuesto de incumplimiento. No se requiere mayor esfuerzo lógico para comprender esto. Ahora bien, es preciso puntualizar algo. El estado de sujeción, como categoría autónoma dentro del conjunto de situaciones jurídicas subjetivas, no se agota en una posición de «sufrimiento» en relación al ejercicio de alguna situación opuesta, desde que tal posición es compartida por todos los sujetos frente al titular de cualquier posición subjetiva tutelada por el ordenamiento. En realidad, aquello que permite identificar al estado de sujeción es esto: su titular, en virtud de la afectación de su esfera jurídica, queda sujeto a la voluntad de un tercero en lo concerniente a la posible modificación de la misma. Esta situación, en consecuencia, expone al sujeto que la padece a una decisión que, proviniendo de otro, es capaz de alterar la configuración de su propia esfera jurídica. En el ejemplo propuesto, esta característica se hace evidente al encontrarse el concedente en la posibilidad de asumir una serie de nuevas situaciones jurídicas subjetivas derivadas del contrato definitivo. Así configurado el estado de sujeción, es claro que nos encontramos ante un tipo de situación de desventaja distinto del deber jurídico. Esta distinción puede ser apreciada claramente cuando se observa que, a diferencia de lo que sucede en el deber, aquí la efectiva subordinación del interés presupuesto por la situación de desventaja se obtiene, no mediante la ejecución de determinada conducta por parte del sujeto «sacrificado", sino a través de la privación de la posibilidad de que el mismo determine la configuración de su propia esfera jurídica. Esto hace, por lo demás, que esta situación -esto es, la sujeciónsea considerada inactiva (el sujeto gravado con la misma no tiene que obrar). 
absoluta (que en términos jurídicos implican la sustracción de la posibilidad de obrar en contra de lo que la norma pretende), vienen a ser entidades jurídicas que, impuestas como sanciones, «cortan» la ilimitada cadena de «reacciones» que, según algunos, tendría que existir para que la teoría de la sanción explique adecuadamente la configuración del deber jurídico. ${ }^{51}$ Con esto, la observación planteada puede considerarse superada.

Ahora bien, visto que la presencia de la sanción constituye algo indispensable para la existencia misma del deber jurídico, conviene indicar que ella no es, como se ha pretendido, una reacción de reproche u odio que el ordenamiento experimenta ante la violación del mandato. En efecto, si, tal como ha sido anotado, el deber jurídico no existe per se; si aquél no es un fin en sí mismo, sino tan sólo un simple medio para el logro de "algo", no se entiende entonces porqué, para ser tal, la sanción tiene que venir impuesta exclusivamente en odio o reproche a la desobediencia, y no simplemente en función a la consecución de aquello que el deber tenía que garantizar.

En realidad, si se mantiene firme la idea de que el deber jurídico protege o permite conseguir un estado de cosas «deseable», no resulta privado de sentido entender que "sanción" viene a ser toda consecuencia que, derivada del incumplimiento de un deber jurídico, y reflejada en la particular esfera jurídica del sujeto transgresor, tenga por objeto (i) recomponer ese estado «deseable» de cosas, en aquellos casos en que éste haya sido alterado; (ii) construir uno nuevo; (iii) frustrar la posibilidad de que se produzca otra alteración de dicho estado de cosas; o, (iv) desalentar nuevos intentos para alterarlo. Así concebida, constitui-

51 Un ejemplo puede ilustrar claramente cómo funciona esta cadena limitada de sanciones. Imagínese que cierto escritor se obliga, frente a determinado editor, a escribir un libro, y que finalmente no cumple con el deber que asume. Ante esta situación, el ordenamiento impone una primera sanción, manifestando de esta forma su reacción ante la violación de la necesitas. Esta sanción consiste en la obligación de reparar los daños causados por el incumplimiento. Ahora bien, imagínese que esta primera sanción -que al igual que la obligación original se traduce en la necesitas de observar determinado comportamiento- es incumplida por el escritor. Ante tal circunstancia, el ordenamiento impone una nueva sanción, que se traduce, no ya en la necesitas de efectuar una conducta, sino en el "padecimiento" de un estado de sujeción. Dicho estado de sujeción tiene como efecto colocar al escritor en una situación tal que la pérdida de sus bienes dependa de la decisión del editor. Esta segunda sanción, a diferencia de la primera, no es, para el escritor, una situación de la cual pueda sustraerse. La cadena de sanciones, en consecuencia, aquí queda interrumpida. 
rían particulares manifestaciones de la sanción, la ejecución forzada, la indemnización de los daños ocasionados, las penas, las multas, etc.

En el entendido de que esta forma de entender a la sanción es la única que puede explicar, de manera uniforme y coherente, las distintas "reacciones" que el ordenamiento jurídico tiene ante un supuesto de violación de una conducta prescrita, se puede afirmar que la sanción es aquella situación jurídica que coloca al sujeto transgresor de un deber jurídico en un estado de "necesidad" -bien absoluto (estado de sujeción) o relativo (deber)- para lograr de esta manera, en orden a cierto estado de cosas, determinado fin que puede consistir, según los casos, (i) en la recomposición o construcción de una situación considerada «deseable» por el ordenamiento jurídico; o, (ii) en la frustración o desaliento de posibles alteraciones de tal situación.

\section{CONCLUSIONES}

El deber jurídico es una situación jurídica subjetiva de desventaja activa, en tanto que se traduce en la necesidad de efectuar un comportamiento normativamente impuesto.

El deber jurídico no es un fin en sí mismo sino solamente un medio para proteger o realizar, tanto situaciones jurídicas subjetivas de ventaja, como situaciones no jurídicas consideradas «deseables» por el ordenamiento.

El deber jurídico requiere, para ser tal, de la presencia externa de una sanción, en tanto que una actitud de indiferencia del ordenamiento ante su violación colocaría al sujeto gravado con el mismo en una situación de libertad. 